\title{
The Prevalence of Childhood Overweight and Obesity in the Children of Noakhali City in Bangladesh
}

\author{
Asma Sultana, Sujan Banik, Mohammad Salim Hossain, \\ Mustahsan Billah and Farjana Afrin \\ Department of Pharmacy, Noakhali Science and Technology University, \\ Sonapur, Noakhali, Bangladesh
}

Correspondence should be addressed to: Mohammad Salim Hossain; pharmasalim@yahoo.com

Received date: 16 May 2014; Accepted date: 12 August 2014; published Date: 28 June 2016

Academic editor: Tomoo Okada

Copyright (C 2016. Asma Sultana, Sujan Banik, Mohammad Salim Hossain, Mustahsan Billah and Farjana Afrin. Distributed under Creative Commons CC-BY 4.0

\begin{abstract}
The prevalence of childhood obesity is a burning topic in developing countries because of its strong relationship with later life obesity and the correlated adverse health consequence. The objective of this study was to find out the prevalence of childhood overweight and obesity in the school going children of the Noakhali city, a coastal region of Bangladesh and to determine its association with the socioeconomic position and other socio-demographic variables. This population-based cross sectional study was conducted in Noakhali in November 2012. A total of 500 respondents were included in this study by following simple random procedure. Socio-economic data, food habit and daily activities data were recorded in this study. Our result revealed that, the prevalence of overweight and obesity between boys and girls $16.7 \%, 25.9 \%$ and $14.3 \%, 19.3 \%$ respectively. This study also revealed that different factors are significant risks for developing obesity such as household monthly income, parent's education and physical activities when compared to reference standard groups. The prevalence of overweight and obesity among boys in this study was high compared to girls.
\end{abstract}

Keywords: Obesity, Overweight, Children, Prevalence.

\section{Introduction}

The prevalence of childhood obesity worldwide has increased significantly during the past two to three decades in developed countries. Obesity is now becoming widely common in developing countries as well, especially in urban areas
(Wang \& Lobstein, 2006). Childhood obesity is a burning topic worldwide because of its strong association with a variety of serious health problems, emerging in childhood and adulthood obesity. Their leads to various problems include psychosocial problems such as social discrimination and reduced self-

Cite this Article as: Asma Sultana, Sujan Banik, Mohammad Salim Hossain, Mustahsan Billah and Farjana Afrin (2016)," The Prevalence of Childhood Overweight and Obesity in the Children of Noakhali City in

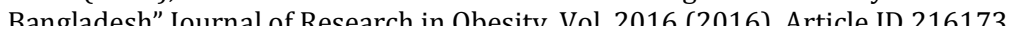


esteem, and physical health problems for instance diabetes mellitus (type 2) and different risk factors associated with cardiovascular diseases (Must \& Strauss, 1999). A projected 300,000 people die every year of illnesses connected to obesity, more than the number killed by pneumonia, motor vehicle accidents and airlines crashes combined (Price, Danielle \& Nicholas, 2000).

Obesity, the most prevalent health issue can be defined as an extreme accumulation of body fat (Lohman, 1987), and childhood obesity is defined as a weight-for-height intemperance of 120 percent of the principle (Dietz, 1983). Although, obesity development mechanism is not clearly understood but it is believed to be a disorder with various difficulties. The key factors such as environmental factors, daily life preferences and the civilizing surroundings play fundamental roles in the rising prevalence of obesity worldwide. Its occurrence is increasing dramatically in spite of age and geographical variation. A report of WHO states that, there were 1 billion overweight people in the world of whom 300 million are obese. A study from Bangladesh in Dhaka city reported that, the prevalence of obesity was considerably superior among the boys (56.8\%) than the girls (43.2\%) (Rahman et al., 2002).

Therefore, the purpose of the present study was to find out the prevalence of childhood overweight and obesity association with its risk factors in the primary school children of Noakhali City, a coastal region of Bangladesh. The findings of this study can present some baseline data on the enormity of this problem, with prominence on school going children in Noakhali, as well as recognize factors to spotlight on when addressing the problem of obesity among children.

\section{Method}

In a community-based, cross-sectional and randomized study carried out in all of Noakhali municipality, a coastal area of Bangladesh. A total of 500 students aged 616 years (277 boys and 223 girls) participated in the study. All the participants willingly joined this study and provided written informed consent. The sampling method was a stratified multistage sampling based on selected primary and secondary schools. The present study protocol was approved by the research ethics committee of Noakhali Science and Technology University, Bangladesh and also ethical informed consent was obtained from parents of all the participants prior to their inclusion into the study.

Detailed information regarding demographic, socioeconomic information including name, sex, age, parent's education, parent's occupation, economic status, food habit etc, behavioral and health status was collected from each study subject. This study also conducted for their daily activities reported by the subjects with their parents in a questionnaire which include their school time, sleep time and free time. The questionnaire was administered by trained personnel.

The WHO criteria for obesity based on the BMI guiding principle were used in this study. BMI is calculated as a way of weight in kilograms divided by height in meters squared $\left(\mathrm{BMI}=\mathrm{kg} / \mathrm{m}^{2}\right)$. Using BMI chart, it is feasible to categorize the level of obesity by reference to internationally accepted ranges, beginning from underweight (BMI < $18.5 \mathrm{~kg} / \mathrm{m}^{2}$ ), normal (BMI 18.5-24.9 $\mathrm{kg} / \mathrm{m}^{2}$ ), overweight (BMI $25.0-29.9 \mathrm{~kg} / \mathrm{m}^{2}$ ) and obese (BMI $\geq 30.0 \mathrm{~kg} / \mathrm{m}^{2}$ ) (Lima et al., 2000). In addition to this BMI chart, we redefined according to CDC BMI percentile growth chart (BMI for children and teens) and Cole established cut off points to define childhood overweight and obesity (Cole et al., 2000).

\section{Statistical analysis}

Descriptive statistics were calculated for all variables using SPSS package software (version 19) and the results were expressed as mean and standard deviations (SD). All values were also expressed in terms of percentage. All reported $p$ values of $<0.05$ were considered as statistically significant. 


\section{Results}

Total cohort included 500 subjects, out of which $55.4 \% \quad(n=277)$ were boys and $44.6 \%(n=223)$ were girls. The mean age of the total study subjects was 9.68 years (SD 1.81 year; range 6-16). Table 1 presents the characteristics of the study subjects. Most of the participants were primary school students.

\section{Table 1: Characteristics of the study population}

\begin{tabular}{|c|c|c|}
\hline \multicolumn{2}{|c|}{ Variables } & Values \\
\hline Cohort & Total participants & $\mathrm{n}=500$ \\
\hline Mean age & Total participants & $9.86 \pm 1.81 \mathrm{yrs}$ \\
\hline \multirow{3}{*}{ Age group (year) } & $6-8$ & $44 \%$ \\
& $8-10$ & $20 \%$ \\
& $10-12$ & $24 \%$ \\
Gender & $12-16$ & $12 \%$ \\
\hline \multirow{3}{*}{ Father's occupation } & Male & $55.4 \%$ \\
& Female & $44.6 \%$ \\
\hline \multirow{3}{*}{ Mother's occupation } & Service holder & $18 \%$ \\
\hline & Business & $24 \%$ \\
& Others & $58 \%$ \\
\hline Monthly income & Service holder & $9.6 \%$ \\
(BDT) & House wife & $90.4 \%$ \\
\hline & $15,000-25,000$ & $18 \%$ \\
& $25,000-35,000$ & $34 \%$ \\
& $35,000-45,000$ & $30 \%$ \\
\hline
\end{tabular}

Among 500 students, $220 \quad$ (44\%) participants were between 6 to 8 years, 100 (20\%) participants were 9 to 10 years, 120 (24\%) participants were 11 to 12 years old and 60 (12\%) were above 12 years old. However, the monthly income among the respondents was divided into four categories, only $18 \% \quad(n=90)$ who earned above 45 thousand BTD per month, $30 \%(n=150)$ earned 35 to 45 thousand BTD per month, 34\% $(n=170)$ earned 25 to 35 thousand BTD per month and 18\% $(n=90)$ who earned only 15 thousand BTD per month.

Based on BMI classification of weight status, among the respondents $20.8 \%$ $(\mathrm{n}=104)$ students were underweight (BMI $\left.<18.5 \mathrm{~kg} / \mathrm{m}^{2}\right), 40.6 \%(\mathrm{n}=203)$ were normal (BMI $\left.18.5-24.9 \mathrm{~kg} / \mathrm{m}^{2}\right), 15.6 \%(\mathrm{n}=78)$ were overweight (BMI 25.0-29.9 $\mathrm{kg} / \mathrm{m}^{2}$ ) and $23.0 \% \quad(n=115)$ were obese (BMI $\geq 30.0$ $\mathrm{kg} / \mathrm{m}^{2}$ ). On the other hand according to CDC BMI percentile growth chart, among the participants $17.6 \% \quad(n=88)$ students were underweight (less than the $5^{\text {th }}$ percentile), $39.0 \%(n=195)$ were healthy weight $\left(5^{\text {th }}\right.$ percentile to less than the $85^{\text {th }}$ percentile), $18.4 \%(n=92)$ were overweight (85 $85^{\text {th }}$ to less than the $95^{\text {th }}$ percentile) and $25.0 \%(n=125)$ were obese (equal to or greater than the $95^{\text {th }}$ percentile) (Fig. 1). In addition, we also try to fit the data according Cole's definition (Cole et al., 2000) to find out the prevalence of childhood overweight and obesity in the present study (Table 2). 


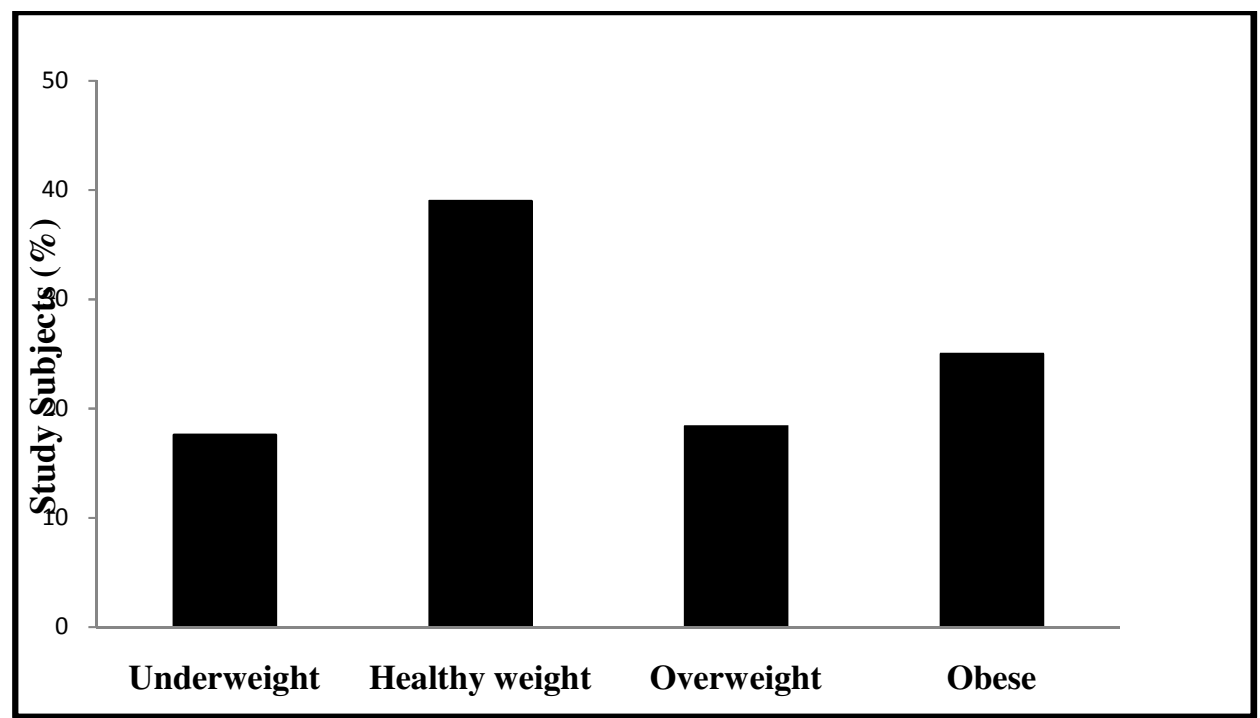

Figure 1: Nutritional status of study subjects. A total of 500 study subjects were evaluated for the prevalence of overweight and obesity according to CDC BMI percentile chart.

Table 2: Prevalence of overweight and obesity among participants based on BMI

\begin{tabular}{|c|c|c|c|c|}
\hline \multirow{2}{*}{ BMI Status } & \multicolumn{4}{|c|}{ Weight Status Categories } \\
\cline { 2 - 5 } & $\begin{array}{c}\text { Underweight } \\
\mathbf{n}(\%)\end{array}$ & $\begin{array}{c}\text { Normal weight } \\
\mathbf{n}(\%)\end{array}$ & $\begin{array}{c}\text { Overweight } \\
\mathbf{n}(\%)\end{array}$ & $\begin{array}{c}\text { Obese } \\
\mathbf{n}(\%)\end{array}$ \\
\hline $\begin{array}{c}\text { Based on WHO BMI } \\
\text { ratio }\end{array}$ & $104(20.8)$ & $203(40.6)$ & $78(15.6)$ & $115(23)$ \\
\hline $\begin{array}{c}\text { Based on CDC BMI } \\
\text { percentile }\end{array}$ & $88(17.6)$ & $195(39)$ & $92(18.4)$ & $125(25)$ \\
\hline $\begin{array}{c}\text { Based on Cole's } \\
\text { definition }\end{array}$ & $96(19.2)$ & $200(40.0)$ & $86(17.2)$ & $120(24)$ \\
\hline
\end{tabular}

Results are expressed as number (\%)

Table 3 presents the relationship between the socio-demographic profile and Body Mass Index (BMI) of the respondents. The prevalence of overweight and obesity among boys and girls was 46 (16.7\%), 72 (25.9\%) and 32 (14.3\%), 43 (19.3\%) respectively and the obtained data were statistically significant $(\mathrm{p}<0.05)$. They show that boys had higher prevalence of overweight and obesity than girls. Based on household monthly income, the children whose families earned above 45,000 thousand BDT per month had higher risk for overweight and obesity than those who came from below 15,000 thousand BDT per month household income i.e., high income showed a significant risk for obesity. 
Table 3: Relationship of socio-demographic profile and body mass index (BMI) among the respondents $(n=500)$

\begin{tabular}{|c|c|c|c|c|c|}
\hline $\begin{array}{l}\text { Profile of the } \\
\text { respondents }\end{array}$ & $\begin{array}{c}\text { Obese } \\
\text { BMI } \geq 30 \\
\text { n (\%) }\end{array}$ & $\begin{array}{c}\text { Overweight } \\
\text { BMI 25-29.9 } \\
\text { n (\%) }\end{array}$ & $\begin{array}{c}\text { Normal } \\
\text { BMI 18.5-24.9 } \\
\text { n (\%) }\end{array}$ & $\begin{array}{c}\text { Underweight } \\
\text { BMI <18.5 } \\
\text { n (\%) }\end{array}$ & $\begin{array}{c}P \\
\text { value }\end{array}$ \\
\hline $\begin{array}{r}\text { Gender } \\
\text { Boys } \\
\text { Girls }\end{array}$ & $\begin{array}{l}72(25.9) \\
43(19.3)\end{array}$ & $\begin{array}{l}46(16.7) \\
32(14.3)\end{array}$ & $\begin{array}{c}108(38.8) \\
95(42.6)\end{array}$ & $\begin{array}{l}51(18.6) \\
53(23.8)\end{array}$ & $0.04^{*}$ \\
\hline $\begin{array}{l}\text { Total family income } \\
15,000-25,000 \\
25,000-35,000 \\
35,000-45,000 \\
>45,000\end{array}$ & $\begin{array}{c}0(0) \\
2(1.2) \\
38(25.3) \\
70(77.8)\end{array}$ & $\begin{array}{c}2(1.2) \\
10(5.8) \\
25(16.7) \\
12(13.3)\end{array}$ & $\begin{array}{c}52(57.8) \\
140(82.4) \\
60(40) \\
5(5.6)\end{array}$ & $\begin{array}{l}38(42.2) \\
18(10.6) \\
27(18) \\
3(3.3)\end{array}$ & \\
\hline
\end{tabular}

Results are expressed as number $(\%)$ and ${ }^{*} \mathrm{P}<0.05$ was considered as significant

Among the respondents, $48 \%$ of obese children spent more than 3-4 hours daily in front of television while $52 \%$ of children of normal weight spent less than 2 hours only. Furthermore, obese children highly prefer different types of juice and junk food compared to normal children. From this chart (Fig. 2), we show that a there is clear correlation between TV watching/juice intake/fast food intake and obesity.

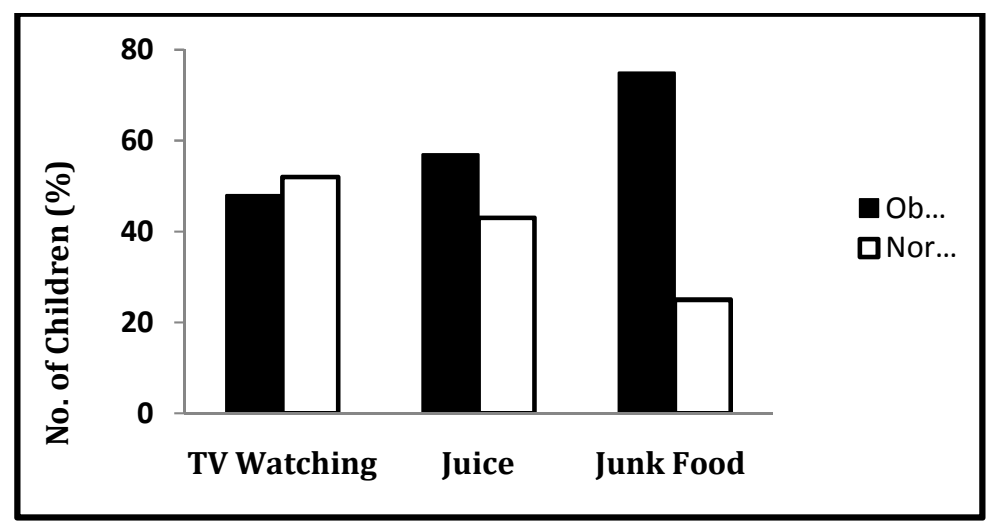

Figure 2: Daily activities of obese children. A total of 500 study subjects were interviewed to know their daily activities and the answers were recorded.

\section{Conclusion}

The outcome of the present study concludes that, a high prevalence of overweight and obesity exists in primary school children in the southern coastal area of Bangladesh. The findings of this study provided obesity and overweight are most prevalent in boys from girls. Our data reveal that, positive energy balance with superior fat ingestion, lack of exercise and fast/processed food cultures to be along with the foremost fundamental factors for rising the prevalence of childhood obesity.
Further studies have to be done to evaluate the foremost causative factors coupled with obesity in primary school going children.

\section{Acknowledgements}

We are grateful to all the team members and participants for their kind cooperation and inspiration throughout the work. 


\section{Reference}

1. BMI for children and teens: [http:// www.cdc.gov/growthcharts/clinical_charts .htm].

2. Cole, T. J., Bellizzi, M. C., Flegal, K. M. and Dietz, W. H. (2000) "Establishing a standard definition for child overweight and obesity worldwide: international survey," BMJ, 320.

3. Dietz, W. H. (1983) "Childhood obesity, susceptibility, cause and management," Journal of Pediatrics, 103 (5) 676-686.

4. Lim, To., Ding, L.M., Zaki. M., Suleiman, A.B., Fatimah, S., Siti, S., Tahir, A. and Maimunah, A.H. (2000) "Distribution of body weight, height and body mass index in a national sample of malaysian adults," Medicinal Journal of Malaysia, 55, 108-128.

5. Lohman, T.G. (1987) "The use of skin folds to estimate body fatness on children 10.Journal of Pediatric Obesity, 1(1) 11-25. and youth," Journal of Physical Education, Recreation and Dance, 58 (9) 98-102.

6. Must, A. and Strauss, R.S. (1999) "Risk and consequences of childhood and adolescent obesity," International Journal of Obesity, 23: supplement 2, pp. s2-s11.

7. Price, R.A., Danielle, R.R. and Nicholas, J.G. (2000) "Resemblance for body mass index in families of obese African American and European American women," Obesity Research, 8, 360-366.

8. Rahman, S. M. M., Kabir, I., Khaled, M.A., Bhuyan, M. A. H., Harun-er-Rashid, Malek, M. A. and Khan, M. R. (2002) "Prevalence and determination of childhood obesity in Dhaka city," $10^{\text {th }}$ ASCON Abstract no.: 173.

9. Wang, Y. and Lobstein, T. (2006) "Worldwide trends in childhood overweight and obesity," International 